\title{
EXPERIMENTAL OBSERVATION OF THE INFLUENCE OF FURNACE TEMPERATURE PROFILE ON CONVECTION AND SEGREGATION IN THE VERTICAL BRIDGMAN CRYSTAL GROWTH TECHNIQUE†
}

\author{
G. T. NeugebnueR $\ddagger$ and W. R. Wilcox \\ Chemical Engineering Department and Center for Crystal Growth in Space, Clarkson University, \\ Potsdam, NY 13699.5700, U.S.A.
}

(Received 13 February 1991)

Abstract-Azulene-doped naphthalene was directionally solidified during the vertical BridgmanStockbarger technique. Doping homogeneity and convection were determined as a function of the temperature profile in the furnace and the freezing rate. Convection velocities were two orders of magnitude lower when the temperature increased with height. Rarely was the convection pattern axisymmetric, even though the temperature varied less than $0.1 \mathrm{~K}$ around the circumference of the growth ampoule. Correspondingly the cross sectional variation in azulene concentration tended to by asymmetric, especially when the temperature increased with height. This cross sectional variation changed dramatically

along the ingot, reflecting changes in convection presumably due to the decreasing height of the melt. Although there was large scatter and irreproducibility in the cross sectional variation in doping, this variation tended to be least when the growth rate was low and the convection was vigorous. It is expected that compositional variations would also be small at high growth rates with weak convection and flat interfaces, although this was not investigated in the present experiments. Neither rotation of the ampoule $\equiv$ nor deliberate introduction of thermal asymmetries during solidification had a significant influence on - cross sectional variations in doping. It is predicted that slow directional solidification under microgravity conditions could produce greater inhomogeneities than on Earth. Combined use of microgravity and magnetic fields would be required to achieve homogeneity when it is necessary to freeze slowly in order to avoid constitutional supercooling.

\section{INTRODUCTION}

The Bridgman technique is widely used for directional solidification of metals, semiconductors, inorganic salts and organic compounds. In the Bridgman-Stockbarger manifestation, an ampoule containing the material to be solidified is slowly translated from a furnace held at a temperature above the melting point of the material into a chamber held below the melting point. In the gradient freeze mode, the ampoule is held fixed in a furnace which has a temperature decreasing continuously from one end to the other. Solidification is caused by slowly lowering the temperature of the entire furnace. In the heat exchange method, coolant is applied to one end of the ampoule. Sometimes at the same time the furnace temperature is slowly decreased.

When Bridgman crystal growth is done with the ampoule held vertically, it is normally desired that the solidification proceed upwards. Thus the temperature at the top of the apparatus is higher than at the bottom of the apparatus. For many years the crystal growth community referred to this arrangement as

+Paper IAF-90-358 presented at the $4 / s t$ Congress of the International Astronautical Federation, Dresden, Germany, 6-12 October 1990.

$\ddagger$ Present address: II-VI Inc., Saxonburg, PA 16506. U.S.A. "thermally stable" and many persons believed buoyancy driven convection was absent. However interest in crystal growth in space led to a closer examination of this assumption. Carlson [1] at Clarkson University and Brown [2] at MIT performed theoretical studies of convection in the Bridgman-Stockbarger technique with a step function change in temperature from the upper chamber to the lower chamber. They found that radial temperature gradients were inevitably present in the melt and could lead to vigorous convection. Initially these results were greeted with skepticism by many in the crystal growth community. Now it is widely accepted that significant convection is always present unless the operation is carried out in space or with a strong magnetic field applied to an electrically conducting melt.

By now many theoretical studies have been performed on buoyancy driven convection in the vertical Bridgman-Stockbarger technique, examining the influence of gravitation level, interface curvature, insulation thickness between the two furnaces, ampoule properties, density variations caused by variations in melt composition, varying temperatures in the heating and cooling chambers, etc. (e.g. [1-7]). Until recently [ 7$]$ it was assumed that the convection was axisymmetric and steady. With one exception [5], theoretical predictions for convection have not been 
compared with experiment because the theoretical work was all done for metals and semiconductors opaque to light. (In Ref. [5], convection was observed in an organic compound. Measured temperatures and interface shapes were used to calculate the convection.)

Potts [8,9] performed experiments on an organic compound (high Prandtl number) heated and cooled by constant temperature baths separated by a diaphragm. The convection in the melt was neither axisymmetric nor steady, although it was very weak. While temperature variations could not be detected in the top heating bath, it was significant that the convection always rose on the side of the ampoule nearest the heater submerged in the circulating bath.

In order to see if either non-uniform heating or misalignment from vertical is necessary to cause the convection to be asymmetric, Neugebauer constructed an apparatus with vertical heating wires embedded in plastic $[10,11]$. The ampoule was embedded in the same plastic, so that there was no fluid between the heating elements and the ampoule. Convection was measured by taking streak photographs of small sulphur particles suspended in organic melts. Even though no circumferential variation in temperature could be measured, the convection was seldom axisymmetric. Furthermore the vertical temperature profile in the heater exerted a very strong influence on the convection in the melt. If the temperature increased with height, the convection became immeasurably small. If the temperature decreased with height, the convection was very vigorous.

The purpose of the research reported here was to determine the influence of heater temperature profile on impurity segregation and to relate this to the convection in the melt.

\section{EXPERIMENTAL METHODS}

The experimental methods are described in detail elsewhere [12]. Naphthalene doped with approx. $0.3 \% \mathrm{~m}$ azulene was used for the experiments. Azulene has an equilibrium distribution coefficient of about 0.3 in naphthalene [13]. The Schmidt number was estimated to be 420 [12].

The primary heater was constructed by wrapping nichrome wire around a $23 \mathrm{~cm}$ long Pyrex tube. An additional glass tube was put inside this tube and another outside it, all fitting together snugly. Below the primary heater was a shorter $6 \mathrm{~cm}$ long heater constructed in a similar fashion and with a separate power supply. Below the heaters were a layer of insulation and then a circulating constant temperature bath.

The azulene-doped naphthalene was contained in $15.6 \mathrm{~mm}$ i.d. Pyrex ampoules. The ingot resulting from directional solidification was transparent except near the top end. This ingot was removed from the ampoule by heating until it slid out. It was cut into sections with a saw. Samples were taken by scratching local areas with glass capillaries, each removing about $0.1 \mathrm{mg}$ of material. The samples were dissolved into acetone and the amount of naphthalene and azulene determined by gas chromatography using a flame ionization detector.

For visualization of convection, a similar apparatus was built with provision for laser slit illumination, as in Refs [10] and [11]. Convection was revealed by taking time exposure photographs of small sulphur particles suspended in salol (phenyl salicylate).

\section{EXPERIMENTAL RESULTS FOR STABILIZING THERMAL CONDITIONS}

By adjusting the temperatures of the two heaters a wide variety of temperature profiles were achieved. These can be classified into two caregories; those in which the temperature increased with height (stabilizing) and those in which the temperature decreased with height (destabilizing). Figure 1 shows the temperature profile used for all of the solidification experiments performed under stabilizing conditions. This profile was measured with thermocouples cemented to the outer wall of the Pyrex ampoule. The radial variation in melt temperature near the solid-liquid interface was about $0.2 \mathrm{~K}$, which corresponds to a Grashof number of about 10. In flow visualization experiments performed under similar conditions, significant convection was observed only near the top of the ampoule where the temperature decreased with height. In the lower portion of the ampoule the sulphur particles settled slowly, but their paths showed slight deviations from the vertical. From these deviations it was estimated that convective velocities near the solid-liquid interface were of the order of $10 \mu \mathrm{m} / \mathrm{s}$.

Figure 2 shows the axial azulene concentration profile for a freezing rate of about $3 \mathrm{~mm} / \mathrm{h}(0.8 \mu \mathrm{m} / \mathrm{s})$,

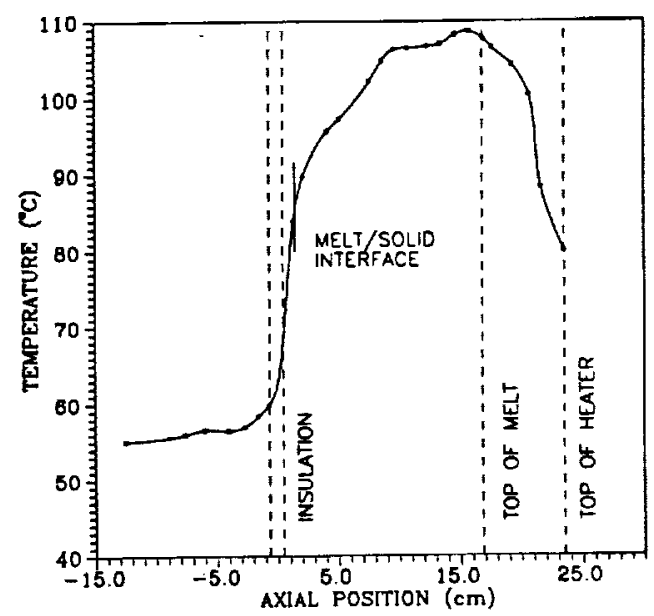

Fig. 1. Axial temperature profile used for all growth experiments in the thermally stabilized configuration. The top of the melt position is that at the beginning of a growth run; during growth the melt level slowly falls as the ampoule is lowered. 


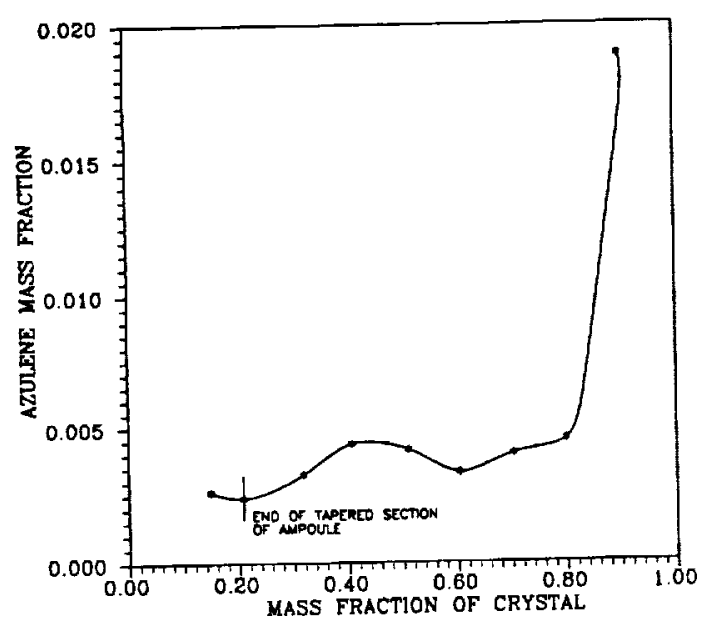

Fig. 2. Axial azulene concentration profile in a naphthalene ingot 30 , which was solidified with $P e=3.2$ in the thermally stabilizing configuration.

which corresponds to a Peclet number $\mathrm{Pe}$ of 3.2 $(\mathrm{Pe}=R V / D$, where $R=7.8 \mathrm{~mm}$ and $D$ was estimated to be $\left.2 \times 10^{-5} \mathrm{~cm} / \mathrm{s}\right)$. This concentration profile is typical of what one would expect to obtain with significant convection in the melt during solidification. Figure 3 shows variations in azulene concentration along a diameter at different positions down the ingot of Fig. 2. (Here $g$ is the mass fraction solidified.) Because the interface was nearly planar, these variations in concentration could only have been caused by convection. Since azulene is rejected by the growing naphthalene, its concentration in-

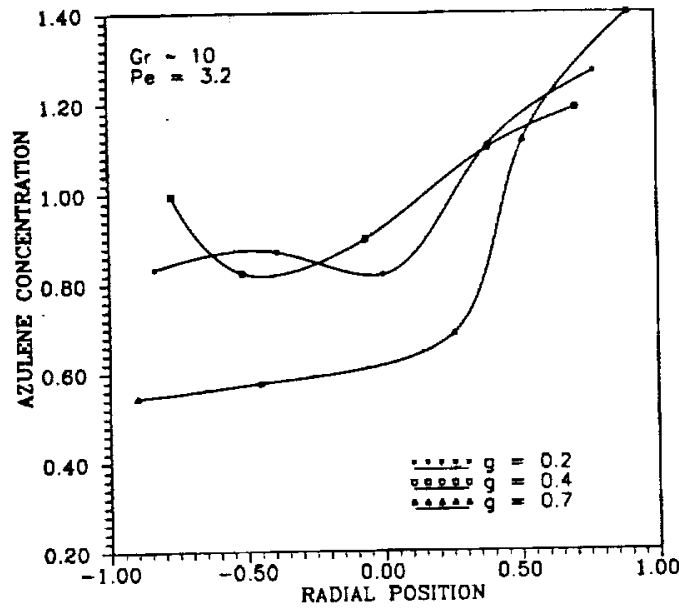

Fig. 3. Diamteric concentration profiles for the same ingot as in Fig. 2, at different axial positions. Here $g$ is the mass fraction of the original charge that had been solidified at the position.

creases as the melt moves along the freezing interface. Thus we expect that convection of the melt along the freezing interface was in the direction of increasing azulene concentration in the resulting solid. In this way we can conclude from Fig. 3 that the convection was asymmetric during solidification of this material.

We define two parameters to characterize the cross sectional variation in azulene concentration and its asymmetry. The "segregation index" is defined as the absolute value of the maximum deviation in concentration from the mean, divided by the mean. Thus in Fig. 3 for $g=0.7$ the segregation index is about 0.45 .

Table 1. Results from experiments performed under the thermally stabilizing condition shown in Fig. 1

\begin{tabular}{|c|c|c|c|c|}
\hline Peclet No. & Crystal & Mass fraction & Segregation & Asymmelry index \\
\hline 3.2 & $\begin{array}{l}30 \\
32^{*} \\
53\end{array}$ & $\begin{array}{l}0.2 \\
0.4 \\
0.7 \\
0.2 \\
0.6 \\
0.7 \\
0.2 \\
0.5\end{array}$ & $\begin{array}{l}0.27 \\
0.19 \\
0.45 \\
0.44 \\
0.11 \\
0.68 \\
0.13 \\
0.31 \\
0.17\end{array}$ & $\begin{array}{l}0.51 \\
0.34 \\
1.56 \\
0.84 \\
0.17 \\
2.8 \\
0.13 \\
0.50 \\
0.02\end{array}$ \\
\hline 5.6 & $\begin{array}{l}35 \\
54 \\
37 \dagger\end{array}$ & $\begin{array}{l}0.6 \\
0.5 \\
\\
0.3 \\
0.6\end{array}$ & $\begin{array}{l}0.22 \\
0.30 \\
0.49 \\
0.64 \\
0.42\end{array}$ & $\begin{array}{l}0.05 \\
0.74 \\
0.76 \\
1.1 \\
0.86\end{array}$ \\
\hline 7.4 & 50 & $\begin{array}{l}0.2 \\
0.5 \\
0.5\end{array}$ & $\begin{array}{l}0.46 \\
0.29 \\
0.57 \\
0.45 \\
0.59 \\
0.59\end{array}$ & $\begin{array}{l}0.44 \\
0.20 \\
0.89 \\
0.17 \\
0.71 \\
0.45\end{array}$ \\
\hline 8.6 & $\begin{array}{l}34 \\
49\end{array}$ & $\begin{array}{l}0.4 \\
0.6 \\
0.2 \\
0.5\end{array}$ & $\begin{array}{l}0.45 \\
0.21 \\
0.29 \\
0.28 \\
0.67 \\
0.51\end{array}$ & $\begin{array}{l}0.21 \\
0.02 \\
0.06 \\
0.20 \\
1.3 \\
0.13 \\
\end{array}$ \\
\hline
\end{tabular}

Ampoule rotated at $2 / 3 \mathrm{rpm}$ during solidification.

Ansule rotentiod to one side of apparatus to yield a temperature difference of $6.4 \mathrm{~K}$ across the outside of the ampoule near the solid-liquid interface. 
The "asymmetry index" is defined as the maximum ratio of concentration at $+R$ to concentration at $-R$, minus 1. In Fig. 3 the asymmetry index for $g=0.7$ is about 1.56 . The segregation index would be 0 for a constant concentration, while the asymmetry index would be 0 for a completely symmetrical concentration profile.

Table 1 summarizes the results for thermal stabilizing conditions. No trends are obvious above the large scatter in values of segregation and asymmetry indices. This reflects the stochastic nature of the convection pattern produced in each experiment. Note that segregation and asymmetry changed dramatically down each ingot, reflecting the change in convection pattern during solidification.

One would expect that at sufficiently high freezing rates the mass transfer in the melt would become diffusion controlled, causing the segregation and asymmetry indices to decline and approach the values expected for diffusion controlled conditions. Although the data suggest there may be a maximum in segregation index at a Peclet number of about 7, there is too much scatter to be certain.

Thermocouple measurements around the outer wall of the ampoule in these experiments showed no circumferential variation in temperature, within a sensitivity of $0.1 \mathrm{~K}$. It is commonly believed that a constant temperature circumferentially must yield axisymmetric convection and impurity concentration patterns. Therefore an experiment was performed in which the ampoule was rotated at $2 / 3 \mathrm{rpm}$, in order to further reduce any circumferential variation in temperature. As shown in Table 1, the segregation and asymmetry indices were unchanged, within experimental scatter (which was large). Similarly, insulating one side of the heater to deliberately produce an asymmetric temperature field did not significantly increase the segregation and asymmetry indices.

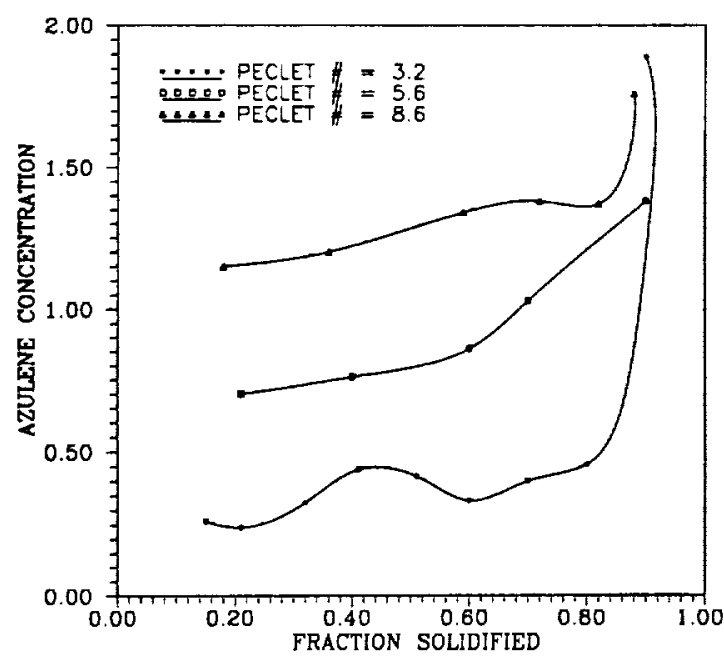

Fig. 4. Axial concentration profiles for ingots solidified at three different rates under the thermally stabilizing condition.

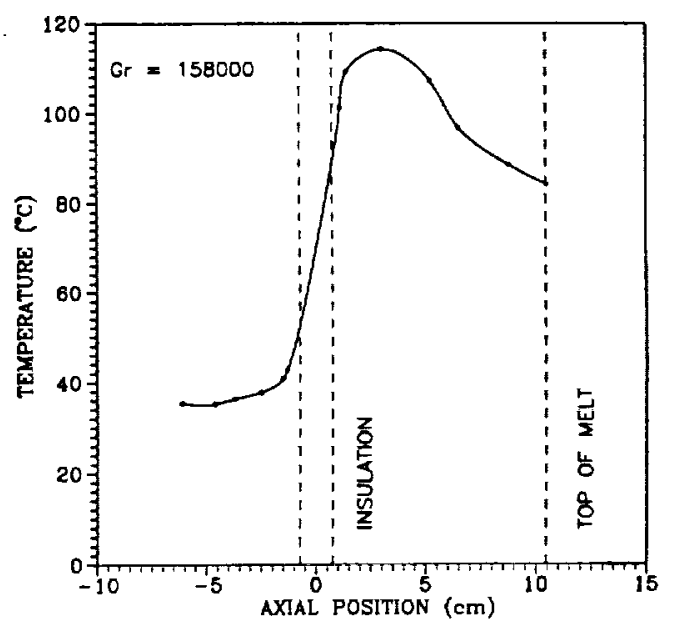

Fig. 5. Typical axial temperature profile for thermally destabilizing condition. Based on the temperature difference between the maximum and the top of the melt, the Grashof number is estimated to have been 158,000 .

Axial concentration profiles also reflect the intensity of convection. Figure 4 shows such profiles for three different freezing rates. The concentration profile at $\mathrm{Pe}=3.2$ is characteristic of convectioncontrolled mass transfer. As Pe was increased, the azulene concentration in the first $80 \%$ of the ingots increased significantly, indicating the decreasing influence of convection.

\section{EXPERIMENTAL RESULTS FOR DESTABILIZING THERMAL CONDITIONS}

Figure 5 shows a typical destabilizing temperature profile. This profile was measured by a fine thermocouple inserted into the melt. Convection was vigorous throughout the ampoule, and was rarely

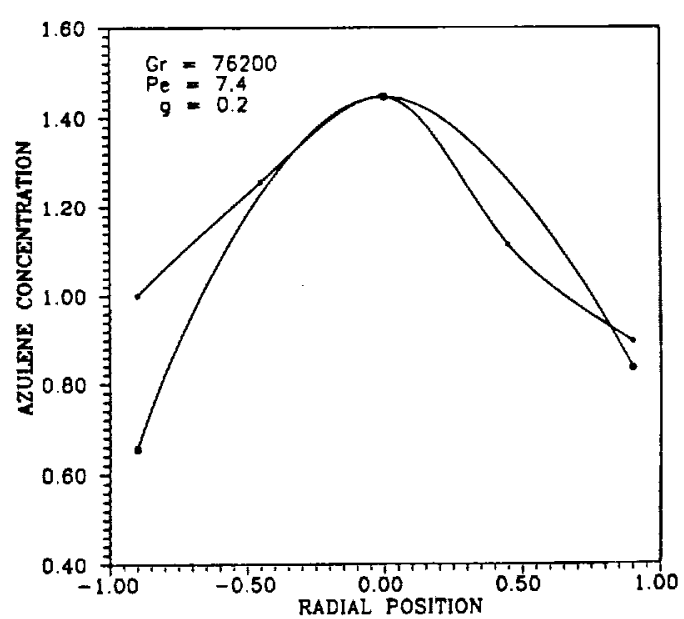

Fig. 6. Concentration profiles along two perpendicular diameters at the position where $20 \%$ of the melt had been solidified. Ingot 51 with destabilizing thermal conditions, $\mathrm{Gr}=76,200$ and $\mathrm{Pe}=7.4$. 
Table 2. Results from experiments performed under thermally destabilizing conditions

\begin{tabular}{|c|c|c|c|c|c|}
\hline Poclet No. & Crystal & Grashof No. & Mass fraction & Segregation & Asymmetry index \\
\hline 3.2 & $\begin{array}{l}41 \\
42\end{array}$ & $\begin{array}{r}55,600 \\
88,500 \\
116,000\end{array}$ & $\begin{array}{l}0.5 \\
0.2 \\
0.5 \\
0.5\end{array}$ & $\begin{array}{l}0.05 \\
0.93 \\
0.93 \\
0.04 \\
0.04 \\
0.04\end{array}$ & $\begin{array}{l}0.05 \\
0.07 \\
0.22 \\
0.02 \\
0.03 \\
0.04\end{array}$ \\
\hline 5.6 & $\begin{array}{l}44 \\
45\end{array}$ & $\begin{array}{r}39,600 \\
121,000\end{array}$ & $\begin{array}{l}0.5 \\
0.5\end{array}$ & $\begin{array}{l}0.17 \\
0.07 \\
0.07\end{array}$ & $\begin{array}{l}0.36 \\
0.08 \\
0.07\end{array}$ \\
\hline 7.4 & 51 & 138,000 & $\begin{array}{l}0.2 \\
0.5 \\
0.5\end{array}$ & $\begin{array}{l}0.45 \\
0.25 \\
0.14 \\
0.26 \\
0.13 \\
0.12\end{array}$ & $\begin{array}{l}0.13 \\
0.27 \\
0.18 \\
0.68 \\
0.13 \\
0.07\end{array}$ \\
\hline 8.6 & $\begin{array}{l}47 \\
48\end{array}$ & $\begin{array}{r}76,700 \\
109,000 \\
158,000\end{array}$ & $\begin{array}{l}0.5 \\
0.2 \\
0.5 \\
\\
0.5\end{array}$ & $\begin{array}{l}0.21 \\
0.47 \\
0.50 \\
0.50 \\
0.15\end{array}$ & $\begin{array}{l}0.46 \\
1.2 \\
0.61 \\
0.38 \\
0.35 \\
\end{array}$ \\
\hline
\end{tabular}

axisymmetric. The convection velocities were on the order of $1 \mathrm{~mm} / \mathrm{s}$, or about 100 times larger than with a stabilizing profile. The convection increased as the temperature gradient was increased. The temperature gradient was characterized by a Grashof number that used the temperature difference between the temperature in the melt and the temperature at the upper surface of the melt measured when the top of the melt was $10.5 \mathrm{~cm}$ above the insulated zone, corresponding to $g=0.2$.

Figures 6 and 7 show typical cross sectional variations in azulene concentration. Visually the diametric concentration profiles often appeared nearly symmetrical, sometimes with a maximum near the center and other times with a minimum. As in the stabilizing configuration, the concentration profiles changed dramatically down each ingot.

As shown in Table 2, the segregation and asymmetry indices again showed a great deal of scatter, but tended to be smaller than with thermally stabilizing

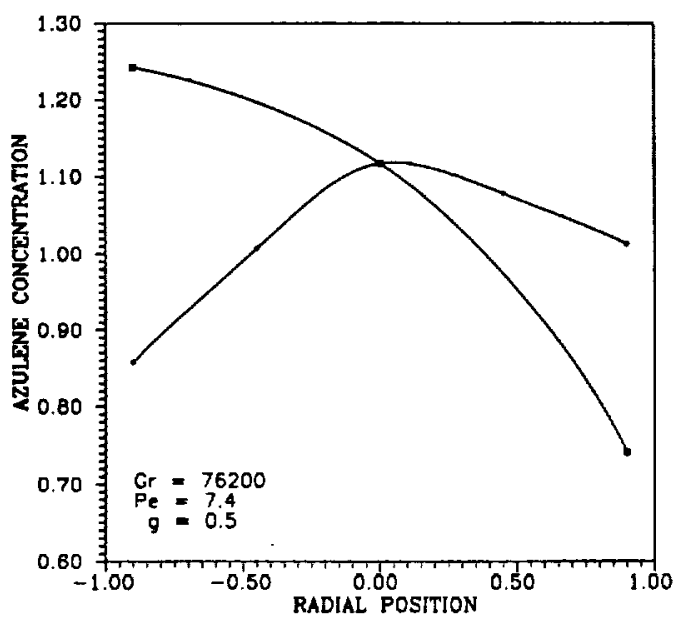

Fig. 7. Concentration profiles along two perpendicular diameters in the same ingot as Fig. 6, except at the position where $50 \%$ of the melt had been solidified. conditions. The asymmetry appeared to be smallest when $\mathrm{Pe}$ was small and $\mathrm{Gr}$ was large (low growth rate with vigorous convection).

\section{IMPLICATIONS FOR SOLIDIFICATION IN SPACE}

A common justification for use of microgravity in directional solidification is that more uniform doping levels should be obtained. However the present results show that under some conditions inhomogeneities could be greater in space than on Earth. In microgravity, weak buoyancy-generated convection will occur. If this weak convection is combined with low freezing rates, greatly increased inhomogeneities could result. Thus when low freezing rates are necessary in order to avoid constitutional supercooling, it may be necessary to combine microgravity and magnetic fields in order to achieve homogeneous crystals.

Acknowledgement-This research was supported by the National Aeronautics and Space Administration under grants NAG8-541 and NAG8-831.

\section{REFERENCES}

1. L. Y. Chin and F. M. Carlson, J. Crystal Growth 62, 561 (1983).

2. C. J. Chang and R. A. Brown, J. Crystal Growth 63, 343 (1983).

3. F. Carlson, private communication, Clarkson University (1990).

4. P. M. Adornato and R. A. Brown, J. Crystal Growth 80, 155 (1987).

5. L. C. Tien and J. O. Wilkes, in Heat Transfer, Volume 1, Heat Exchangers (Edited by U. Grigull and E. Hahne). Elsevier, Amsterdam (1970).

6. M. J. Crochet, F. Dupret, Y. Ryckmans, F. T. Geyling and E. M. Monberg, J. Crystal Growth 97, 173 (1989).

7. W. Arnold, D. Jacqmin, R. Gaug and A. Chait NASA. Lewis), 28th AIAA Aerospace Sciences Meeting, Reno, Nev. (1990).

8. H. Potts, M.S. thesis, Clarkson University (1984)

9. H. Potts and W. R. Wilcox, J. Crystal Growth 74, 434-445 (1986) 
10. G. Neugebauer, M.S. thesis, Clarkson University 12. G. Neugebauer, Ph.D. thesis, Clarkson University (1986).

11. G. Neugebauer and W. R. Wilcox, J. Crystal Growth 89, 143-154 (1988). (1989).

13. N. Karl, in Crystals: Growth, Properties and Applications. Springer, New York (1981). 